CUAD. CONTAB. / BOGOTÁ, COLOMBIA, 17 (44): 493-519 / JULIO-DICIEMBRE 2016 / 493

\title{
Indicadores de contabilidad social con miras a diseñar políticas de mejoramiento de calidad de vida*
}

doi:10.11144/Javeriana.cc17-44.icsm

\section{Fredy González-Castillo}

Contador público. MSc en contabilidad internacional y auditoría de gestión, Universidad Santiago de Chile, Chile. Docente catedrático, Universidad Cooperativa de Colombia, sede Santa Marta.

Correo electrónico: fredy.gonsazalez@campusucc.edu.co, fjgonzalez@sena.edu.co

\section{Daulis Lobatón-Polo}

Contador público. Doctor en ciencias gerenciales, Universidad Dr. Rafael Belloso-Chacín, Maracaibo, Venezuela. Docente investigador, Universidad Cooperativa de Colombia, sede Santa Marta.

Correo electrónico: Daulis.polo@campusucc.edu.co; dlobatonpolo@hotmail.com

\section{Gregoria Polo de Lobatón}

Contadora pública. Doctora en ciencias gerenciales, Universidad Dr. Rafael Belloso-Chacín, URBE, Maracaibo, Venezuela. Docente investigador, Universidad Cooperativa de Colombia, sede Santa Marta.

Correo electrónico: gregoria.polo@campusucc.edu.co; gregpolo1@hotmail.com

\footnotetext{
* Proyecto subvencionado por la Universidad Cooperativa de Colombia, sede Santa Marta, convocatoria CONADI, código 4172008 .
} 
Resumen Este artículo resultado de la investigación que tuvo como propósito la construcción de indicadores sociales de calidad de vida para la contabilidad social, útiles para caracterizar la calidad de vida de los estudiantes de contaduría pública de la Universidad Cooperativa de Colombia, sede Santa Marta, se apoyó en metodología cualitativa descriptiva fundamentada en la sistematización de experiencia, utilizó técnicas de revisión documental y el taller, los análisis, las conclusiones y la información aportada por los actores, se clasificaron y sistematizaron para con base en ella construir y proponer indicadores que posibiliten un avance de la contabilidad social, en el fortalecimiento de la gestión de las entidades privadas o públicas. Concluye que la contabilidad social es una nueva visión de la contabilidad que incluye información cualitativa ventajosa para la toma de decisiones, y que con base en la respondabilidad constituye el soporte de sus grupos de interés.

Palabras clave Contabilidad social; calidad de vida; indicadores de contabilidad social y respondabilidad

\section{Códigos JEL M40}

\section{Social Accounting Indicators Aimed at the Design of Policies for the Improvement of Quality of Life}

\footnotetext{
Abstract This article is the result of a research project that had as purpose the construction of social quality of life indicators for social accounting, which are useful to characterize the quality of life of public accounting students of the Universidad Cooperativa de Colombia, Santa Marta campus. The study was based on the use of qualitative descriptive methodology founded on the systematization of experience; we used document review techniques and workshops. The analysis, conclusions, and information provided by the actors were classified and systematized as to use it as the basis for the proposal of indicators that allow the advancement of social accounting in the strengthening of the management of private or public entities. We con-
}

clude that social accounting is a new vision of accounting that includes qualitative information that is advantageous for decision making, and that, based on accountability, it constitutes the support of its stakeholders.

Keywords social accounting; quality of life; social accounting and responsibility indicators

\section{Indicadores de contabilidade social visando desenhar políticas de melhoramento de qualidade de vida}

Resumo Este artigo resultado da pesquisa que teve como propósito a construção de indicadores sociais de qualidade de vida para a contabilidade social, úteis para caracterizar a qualidade de vida dos discentes de contabilidade pública da Universidade Cooperativa da Colômbia, sede Santa Marta, foi apoiada em metodologia qualitativa descritiva fundamentada na sistematização de experiência. Utilizaram-se técnicas de revisão documental e a oficina, as análises, as conclusões e a informação fornecida pelos atores. Baseada nela classificaram-se e sistematizaram-se para construir e propor indicadores a possibilitar um avanço da contabilidade social, no fortalecimento da gestão das entidades privadas ou públicas. Conclui que a contabilidade social é uma nova visão da contabilidade que inclui informação qualitativa vantajosa para a tomada de decisões, e que, com base na responsabilidade constitui o suporte de seus grupos de interesse.

Palavras-chave Contabilidade social; qualidade de vida; indicadores de contabilidade social e responsabilidade

\section{Introducción}

Hoy, el incremento del contexto económico internacional estimula a las organizaciones para diseñar y aplicar programas sociales con políticas y prácticas responsables en función de 
mejorar la calidad de vida desde la dimensión económica, ambiental y social. En este sentido, se incorporan propuestas de modelos con indicadores de comportamiento con el propósito de contribuir al desarrollo de una actuación caracterizada por la responsabilidad ante la sociedad y su entorno.

Las universidades son sedes de comunicación del saber mediante relaciones interpersonales dirigidas a transmitir conocimientos, pero sobre todo a comunicar ideas y buscar formas apropiadas y eficaces de adquirirlos, criticar los recibidos y avanzar en la búsqueda de otros nuevos. Su finalidad no es solamente la comunicación de un saber adquirido, sino el despertar de la iniciativa, la creatividad y el espíritu de búsqueda de impactos sociales y ambientales de cuantos intervienen en ella.

Es importante reconocer que si bien es cierto que la contabilidad social puede dar cuenta del impacto social y ambiental de las empresas en la sociedad, no es menos cierto que puede situarse por fuera de ellas, para dar cuenta del estado actual y las proyecciones del hombre, al asumir determinados roles sociales, como el de estudiante por ejemplo, o en su misma cotidianidad. En este sentido, se debe señalar que la intención de la presente investigación es buscar respuesta al interrogante: ¿cuáles indicadores de contabilidad social se podrían construir para caracterizar, la calidad de vida de los estudiantes de contaduría pública de la Universidad Cooperativa de Colombia, seccional Santa Marta?

Para responder al interrogante, se establece como objetivo general: construir los indicadores sociales de calidad de vida para la contabili- dad social, útiles para caracterizar la calidad de vida de los estudiantes de contaduría pública de la Universidad Cooperativa de Colombia, sede Santa Marta.

En lo que a la justificación de la investigación se refiere, se pretende generar como aporte una propuesta con una perspectiva innovadora, que a diferencia de lo que ya se ha hecho, se fundamenta en tres aspectos claves: a) la formulación de indicadores sociales desde la óptica de la contabilidad social; b) la participación activa de los estudiantes de contaduría pública (directamente con ellos - no exclusivamente con los investigadores - se abordó todo el proceso investigativo para llegar a formular los indicadores); y c) el estudio de los factores asociados a la calidad de vida, para fundamentar en ellos los indicadores, para valorar en su justa medida el disfrute de lo material, de lo externo a las personas y de lo presupuestal público, pero integrados con otros factores generalmente no estudiados, como las necesidades de ocio, afecto y libertad, entre otros, y con dimensiones cualitativas y cuantitativas de los fenómenos.

Del mismo modo, esta investigación se justificó para cumplir el requerimiento de contribuir al desarrollo de la contabilidad social. En esta oportunidad, se aportará en esa vía, al construir indicadores basados en las categorías propias de la calidad de vida y en un sentido integral, para caracterizar a los miembros de la comunidad estudiantil. Además, para el mejoramiento de calidad de vida, en la medida en que constituye en el insumo para llegar a) estimular el mejoramiento real de las condiciones de vida de los estudiantes de 
contaduría pública o una comunidad susceptible de ser analizada para los fines pertinentes; b) trascender con los participantes en la investigación, desde modelos cuantitativos de calidad de vida, hacia mejores posibilidades de realización personal y social; c) estimular organizaciones de base y consolidar liderazgos dentro de la comunidad académica; y d) necesidad de contar en la Universidad y en el programa, con una base de datos que permita el diseño de políticas transformadoras del bienestar institucional.

Este proyecto se realizó para generar transformaciones importantes en la contabilidad social, contribuir y aportar una herramienta eficaz para el desarrollo de la sociedad, en la calidad de vida de sus participantes y en los procesos internos del programa de contaduría pública y de la Universidad Cooperativa de Colombia, seccional Santa Marta; además, se convierte en un estudio piloto, que podría extenderse luego a otros programas de la misma Universidad, incluso a la Educación Superior, y a otras entidades, y actores (por ejemplo, a los docentes, a la comunidad académica en general o a otros grupos sociales).

\section{Contabilidad y calidad de vida}

La búsqueda preliminar no encontró evidencia de que estudios de esta naturaleza en la Universidad, en el sentido como se propuso, es decir, integral, participativo y desde la cotidianidad de la comunidad estudiantil; mucho menos se ha abordado este tema auscultando la calidad de vida desde el vínculo de la contabilidad social, en el marco del claustro universitario; tampoco se encontraron estudios que intentaran construir indicadores de calidad de vida válidos para la contabilidad social.

No obstante, hay algunos estudios sobre la relación entre la contabilidad y la calidad de vida, como el de Marco Antonio MachadoRivera (2000), quienes consideran que es necesario que los contables cuestionen sobre el papel de la contabilidad como factor del desarrollo nacional, para trascender el enfoque tradicional de ser tan solo emisores de cifras y estados financieros; además, estos autores plantearon que la herramienta más útil para asumir con altura el compromiso con el bienestar de la colectividad es la investigación contable. Los mencionados autores se apoyan en las conclusiones del trabajo de Marco Antonio Machado-Rivera (2000), quien razonó que la responsabilidad social del contador público exige cumplirles a la profesión y a la disciplina, para procurar mejores niveles de concientización y generación de calidad de vida.

Ahora bien, desde una perspectiva general, el tema de la calidad de vida ha sido abordado por otros actores, que enfatizan siempre en el disfrute de aspectos materiales (por ejemplo: si tiene casa u otras comodidades), en otros casos (en los presupuestos públicos, el disfrute la salud, vivienda, educación) y en lo externo a las personas (su nivel de ingresos); del mismo modo, las bases de datos con que cuenta actualmente la Universidad sobre su comunidad estudiantil solo tienen en cuenta esos mismos factores; sin embargo, el punto de interés no es la evaluación o el fortalecimiento de la calidad de vida, sino simplemente establecer el factor tarifario para atender criterios de valoración 
para el cálculo de los conceptos de matrícula o de algunos servicios de bienestar.

La investigación se apoyó en conceptualizaciones que guiaron la argumentación del proceso metodológico para lograr los resultados tomando como base los referentes iniciales de contabilidad social, pues este concepto siempre ha sido ligada al ámbito empresarial, en la medida en que se ha considerado que tiene su razón de ser en una necesidad de la empresa de contar con información pertinente para tomar decisiones inteligentes en relación con la gestión social para cumplir así su responsabilidad social (Araujo-Ensuncho, 2002).

En la revisión de otros autores que se han aproximado al concepto de contabilidad social, Françoise Rey (1978) argumenta que la contabilidad social se esfuerza por identificar y medir los efectos económicos y sociales de la empresa sobre la sociedad y también los efectos de la sociedad sobre la empresa; Ricardo Pedreira-Pérez (1980) la define como aquella rama de la ciencia contable que analiza, registra y describe las operaciones de contenido socioeconómico; Ahmed Riahi-Belkaoui (1992) afirma que las empresas deben rendir informes sobre aquellas actividades que afectan a la sociedad, ello se justifica siempre y cuando publiquen información sobre contabilidad social y esta sea tenida en cuenta para tomar decisiones por parte de los usuarios individuales, y que el mercado de capitales la utilice para agregar valores; mientras tanto para Jack Araujo-Ensuncho (1995), la contabilidad social es un subsistema de la contabilidad referido a hechos sociales, tanto del recurso humano en la empresa, como de los que suceden fuera de ella, en la comunidad en la que está inserta.

Por otra parte, según Rob Gray, Dave Owen y Carol Adams (1996), la empresa tiene una responsabilidad social y medioambiental con la sociedad; en esta vía, la contabilidad sirve para rendir cuentas. Estos autores cuestionan el papel tradicional de la contabilidad y dejan sentado que la democracia no puede limitarse solo a responder a los intereses del capital, y afirman que la armonía social y el consenso solo son posibles si se tienen en cuenta otros tipos de intereses.

Otro enfoque importante es el de la teoría del beneficio verdadero. Ralph W. Estes (1972) dice que el resultado de la empresa ignora sus efectos sociales y medioambientales y considera que una contabilidad social podría medir la contribución neta de la empresa a la sociedad si tuviera en cuenta estas dos variables.

En ese sentido, en los planteamientos de la General Accounting Office, GAO, de Estados Unidos (1986), la contabilidad social y medioambiental es el proceso de comunicar los efectos sociales y medioambientales de la actividad económica de las organizaciones a determinados grupos de interés en la sociedad y a la sociedad en su conjunto, e implica extender la responsabilidad de las organizaciones más allá del papel tradicional de proporcionar estados financieros a los propietarios del capital.

De igual forma, la investigación consideró importantes los planteamientos de Marco Antonio Machado-Rivera (2004), en el sentido de que lo social refleja altos niveles de complejidad, que deben ser acometidos con modelos interpretativos y representativos, y por marcos 
conceptuales e instrumentales apropiados, lo cual no es de ningún modo ajeno a la contabilidad. Frente a esta realidad, desde un enfoque científico, ha tenido que ir ampliando su espectro desde lo micro hasta lo macro contable. Así, hoy, la contabilidad social debe abordar fenómenos extraños a la contabilidad en tiempos muy recientes, como el capital humano e intelectual, los recursos naturales y del medio ambiente, la cultura, la responsabilidad social y la contabilidad nacional y de agregados sociales. A todos estos enfoques, sumamos la calidad de vida.

Desde esta óptica, el papel de lo ambiental se entiende como un componente más a estudiar, en lo referente a la calidad de vida. Por último, aunque se considera la relevancia de las dimensiones cuantitativas, monetarias y financieras, propias de la contabilidad tradicional, la búsqueda se orientó también hacia la identificación o proposición de otras expresiones, concretamente las de orden cualitativo.

La investigación también se apoyó en el concepto de calidad de vida, por lo que retomó el documento Calidad de vida. Evolución del concepto y su influencia en la investigación y en la práctica, firmado por María Gómez-Vela y Eliana Sabeh (2000), del Instituto Universitario de Integración en la Comunidad, INICO, Facultad de Psicología, Universidad de Salamanca; y las formulaciones de diversos autores sobre calidad de vida en la historia reciente y desde las perspectivas de distintas disciplinas, que han desarrollado iniciativas de investigación aplicada para avizorar algunas tendencias en los futuros años.

Es importante reconocer que el concepto de calidad de vida ha suscitado el interés del hombre desde siempre; sin embargo, su estudio desde la perspectiva científica solo se abordó a partir de 1960. Vale decir también que a partir de los años 80 puede hablarse del despegue definitivo de la investigación respecto del término (Gómez-Vela \& Sabeh, 2000).

En efecto, según se infiere de un trabajo de Igone Arostegi Barandika en 1998, citada por María Gómez-Vela y Eliana Sabeh (2000), desde principios de los años 80, la calidad de vida comienza a ser definida como un concepto que no solo integra las áreas de la vida humana de manera multidimensional, sino que hace referencia a condiciones tanto objetivas como subjetivas; así mismo, el concepto de calidad de vida se comienza a diferenciar del concepto de indicadores sociales, que había surgido de la necesidad de medir el bienestar humano y las consecuencias de la industrialización por medio de datos objetivos, aunque luego contempló datos subjetivos.

Aunque no es fácil encontrar un acuerdo entre los investigadores respecto del concepto de calidad de vida, de todas maneras, como lo reconoce Robert Schalock (1996), citado por María Gómez-Vela y Eliana Sabeh (2000), el concepto está ganando cada vez más espacio como elemento de mejora de la sociedad. En otras palabras, el concepto viene siendo utilizado eficazmente para propósitos como la evaluación de las necesidades de las personas y sus niveles de satisfacción, la evaluación de los resultados de los programas y servicios humanos, la dirección y guía en la provisión de estos servicios y la formulación de políticas nacionales e internacionales dirigidas a la población en general o a otras más específicas como la población con discapacidad. 
No obstante lo observado, para el análisis de la calidad de vida y la formulación de indicadores asociados a la contabilidad social, con miras a la posterior caracterización de la calidad de vida de la comunidad estudiantil del programa de contaduría pública de la Universidad Cooperativa de Colombia, seccional Santa Marta, los investigadores han considerado pertinente tomar como referencia el modelo de desarrollo a escala humana, propuesto por Manfred MaxNeef, Antonio Elizalde y Martín Hopenhayn (2010); que se entiende como una concepción alternativa de desarrollo, dado que implica unos presupuestos distintos a los convencionales.

Pero desde la propuesta de desarrollo a escala humana, que se ha presentado como fundamento de esta investigación, es imprescindible tomar en cuestión condiciones internas y externas a las personas, trascender las magnitudes de los presupuestos públicos y poner a los individuos frente a procesos autogestionarios, que se centran en el imperativo de resolver las "necesidades humanas fundamentales".

No obstante, uno de los aspectos más importantes es que las necesidades humanas fundamentales se interpretan como potencialidades y no como carencias, por lo tanto se puede comprometer de manera directa a las personas para que asuman la transformación de la realidad. Así mismo, no basta con identificar los recursos que el medio pone a su disposición, sino que además es necesario examinar en qué medida el medio reprime, tolera o estimula la posibilidad de disponer de ellos.

Finalmente, las necesidades humanas fundamentales distinguen entre bienes económicos y satisfactores. Los satisfactores son todo aquello que representa formas de ser, tener, hacer y estar, que contribuyen a la realización de necesidades humanas y debe diferenciarse entre satisfactores destructores, inhibidores, singulares, sinérgicos y seudosatisfactores.

Por último, respecto de la calidad de vida, si se tienen claras las variables y dimensiones que le son inherentes, de acuerdo al enfoque teórico que se adopte, es posible medir o evaluar los logros alcanzados por medio de indicadores. En términos generales, puede leerse en el trabajo de Juan Cristóbal Bonnefoy (2006), que al conceptuar sobre los indicadores, algunos autores los han definido como la unidad de medida que permite cuantificar el alcance de una meta (Cohen \& Franco, 1992); además, como unidades de análisis de una evaluación, con ellos se puede llegar a establecer un juicio fundado (Ventosa-Pérez, 1992) y la medida específica y objetivamente verificable de los cambios o resultados de una actividad (Ander-Egg, 1996). Todos estos autores coinciden en que para formular indicadores deben establecerse unas metas, con unos insumos y unos procedimientos previamente determinados y a unos plazos para alcanzar los logros esperados.

No debe perderse de vista que un aspecto determinante en el trabajo es el énfasis en la construcción de indicadores cualitativos de calidad de vida que sirvan de complemento a los tradicionales; por lo tanto, acogiendo lo dicho por Pedro Delgado y Tulia Salcedo (2008), es importante para la sociedad construir los indicadores, como la violencia, la inseguridad, el desplazamiento, el desempleo y sus derivaciones, la falta de oportunidades o el nivel creciente de deterioro ambiental. Es decir, asumir una 
perspectiva integral de la calidad de vida, de manera que los indicadores diseñados en esa misma vía, puedan servir de bases firmes para la caracterización de la calidad de vida de los estudiantes, u otros actores de la comunidad académica, con base en los indicadores de contabilidad social resultado de la presente investigación.

Es importante rotular la necesidad de reunir y sistematizar la información del área social, en un documento público, en que se pueden cuantificar los datos mediante los indicadores sociales que son elementos básicos de un balance social, afirma Hernando CamposMenéndez (1978). El Desarrollo de la Responsabilidad Social (DERES, 2004) define el balance social como un reporte en el cual se da cuenta de los proyectos, beneficios y acciones sociales dirigidas a las distintas partes interesadas, ya sean estos empleados, inversionistas, analistas de mercado, accionistas o la comunidad en su conjunto.

En cuanto a los modelos de balance social, es oportuno mencionar el Global Reporting Initiative (GRI), organización creada en Estados Unidos en 1997 con sede en Ámsterdam, Holanda, cuya misión es proporcionar y difundir un marco mundial de trabajo común para la elaboración de las Memorias de Sostenibilidad, con un lenguaje homogéneo y parámetros comunes, que sirva como base para comunicar los temas relacionados con la sostenibilidad de una forma clara y transparente para todas las organizaciones y los interesados. Este es el norte de la presente investigación.

Basados en las diferentes guías de la Global Reporting Initiative: de la Global Reporting Initiative (GRI), la G4 es un referente relevante para la interpretación de indicadores. En esta guía, encontramos tres (3) categorías para el enfoque de gestión de indicadores: categoría económica, medio ambiente y desempeño social; esta última subdividida en prácticas laborales y trabajo digno, derechos humanos, sociedad y responsabilidad sobre productos, lo que para este documento amplía la perspectiva de interpretación de indicadores sociales en la construcción de un balance social.

\section{Materiales y métodos}

El enfoque metodológico fue predominantemente cualitativo, en un nivel descriptivo de conocimiento, acogiendo lo dicho por Roberto Hernández-Sampieri, Carlos Fernández-Collado y Pilar Baptista-Lucio (2010). En esta vía se buscó elaborar indicadores de contabilidad social adecuados, útiles para la caracterización de la calidad de vida de los estudiantes del programa de contaduría pública de la Universidad Cooperativa de Colombia, sede Santa Marta, con la intención, de que a partir de allí se logren modificar hechos y situaciones concretas a partir de la contabilidad social. El universo fue la población total de los estudiantes de contaduría pública de la Universidad Cooperativa de Colombia, seccional Santa Marta; de manera arbitraria se establecen como muestra los tres últimos niveles en estos momentos, es decir, octavo, noveno y décimo semestre.

Los indicadores de calidad de vida asociados a la contabilidad social fueron construidos por el equipo de investigación, en conjunto con los participantes, a partir de información aportada por la revisión de bibliografía especializada y con la 
realización de talleres participativos, en el marco de los cuales se analizaron y profundizaron en el tema de la investigación, de acuerdo al Departamento Nacional de Estadística, DANE (2013).

La metodología rescató como actores principales a los estudiantes del programa de contaduría pública de la Universidad Cooperativa de Colombia, seccional Santa Marta, que reflexionaron sobre contabilidad social, calidad de vida e indicadores de calidad de vida, al confrontar y evaluar distintos enfoques, establecer las necesarias relaciones entre los conceptos, reconocer y apropiarse de conocimientos nuevos; ello entienden su papel como gestores del conocimiento y de su propio bienestar y, en fin, asumen de este modo los fundamentos iniciales de un compromiso más decidido por el mejoramiento de su calidad de vida no solo personal, sino profesional y social. De igual manera, esta investigación se orientó bajo la sistematización de experiencias apoyadas en los argumentos de Marfil Francke y María de la Luz Morgan (1995) y Antoni Verger i Planells (2002).

\section{Resultados de la investigación}

\section{Nociones que aportan a la contabilidad social}

Los resultados de la investigación determinan que la contabilidad social como nueva visión de la contabilidad y desde las perspectivas teóricas de los autores seleccionados (Machado, 2004; Mathews, 1993; Valencia, 2004), la contabilidad social se interpreta como un instrumento útil en la toma de decisiones para el diseño de políticas públicas empresariales privadas y desde lo público el mismo Estado, para mejorar la calidad de vida de los usuarios a partir de los indicadores construidos para la evaluación de las actuaciones empresariales, y se considera que la información relacionada constituye un elemento generador de desarrollo.

Por los resultados de la investigación, el concepto de contabilidad armoniza con los planteamientos de M. Reg Mathews (1993), quien lo precisa como un sistema de información para administrar datos relacionados con lo social, refleja aspectos no económicos de la organización, al tiempo que permite responder por sus actuaciones frente a la comunidad o entorno en donde actúa, y en lo relacionado con la gestión empresarial como su interacción con la sociedad, sirva para diseñar y ejecutar programas para intentar calidad de vida a los miembros de la empresa y la sociedad. Se puede inferir que el concepto de contabilidad social es una forma de expresión de responsabilidad social empresarial (RSE). Y agregar que la contabilidad social como sistema de información considera aspectos sociales como medio ambiente, éticos, recursos humanos, capital humano, el patrimonio y todo recurso económico generador de ingresos; la responsabilidad social y el impacto que genera su actuación se pueden medir por medio de indicadores y políticas con toda la información que se concibe ${ }^{1}$.

Luego, la contabilidad social es un sistema de información que brinda la oportunidad de incorporar aspectos sociales, útil para recopilar fundamentos y formas de construir los correctivos para minimizar impactos forjados en la

1 Resultado de las entrevistas en los talleres con los estudiantes de contaduría pública de la Universidad Cooperativa de Colombia, sede Santa Marta. 
sociedad con la asistencia de indicadores, se instaura como soporte de la toma de decisiones y para definir acciones que ayuden a la construcción e implementación de programas para las buenas operaciones de la empresa que contribuyan a mejorar la calidad de vida de sus grupos de interés, como se ve en el gráfico 1 .

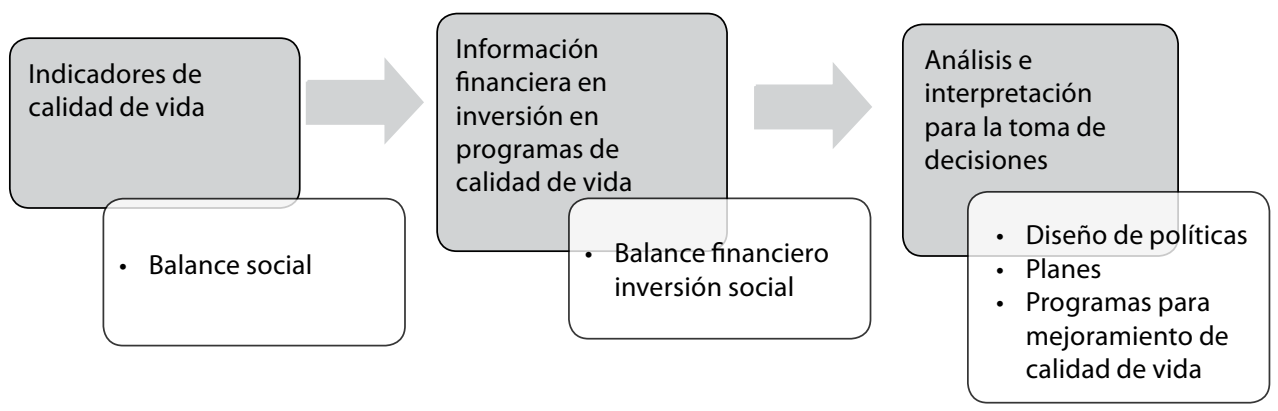

Gráfico 1

La contabilidad social: un sistema de información para la toma de decisiones

Fuente: elaboración propia

Referirse a la interpretación de Marco Antonio Machado (2004) es reconocer que la contabilidad deja por fuera la valoración de hechos sociales no incluidos en ella. De tenerla en cuenta, como modelo social interpretativo y representativo, la contabilidad social idearía la formación de personas, y de los contadores como profesionales integrales. De esta manera, construiría una nueva visión de contador y aportaría elementos de juicio para tomar decisiones, para dar cuenta de los bienes y de la sanidad para actuar bajo condiciones de calidad de vida ${ }^{2}$.

Los aspectos sociales como capital humano e intelectual son elementos cualitativos que, incluidos en la contabilidad, generan los rasgos o características de la contabilidad social.

2 Interpretación de los datos cualitativos en la información relacionada con la investigación, apoyados en los comentarios sobre contabilidad social desde la perspectiva de Marco Antonio Machado-Rivera (2004).
La importancia que los aspectos cualitativos le dan a la contabilidad permite ampliar su horizonte; lo cualitativo dentro de la contabilidad entrelazado con lo cuantitativo mejora la información para una acertada toma de decisiones.

$\mathrm{Al}$ esgrimir los aspectos cualitativos como uno de sus roles, la contabilidad toma su esencia como sistema de información, amplía el campo de actuación y estudio de los contadores para implementar los procesos que la hagan realidad. Es importante reconocer que la necesidad de incluir los aspectos cualitativos en la contabilidad ha despertado inquietudes en las empresas sobre la actualización de la información para la toma de decisiones.

Un contador que además de tener en cuenta los aspectos financieros de la contabilidad, también considere aspectos sociales, con amplias capacidades para la toma de decisiones y con visión futurista, interviene en procesos para 
apuntar hacia el desarrollo sostenible, genera en las empresas y en su entorno respeto por la sociedad y el medio ambiente. Esto lo convierte en un contador con la capacidad de transformar la información financiera en términos de interés para la sociedad, es decir, un nuevo perfil social del contador.

\section{Calidad de vida, una visión académica base para la contabilidad social}

Desde los planteamientos de Astrid Lorena Perafán y William Andrés Martínez-Dueñas (2004), la calidad de vida de la población se mide de acuerdo con su nivel adquisitivo para acceder a bienes y servicios públicos asociado con el nivel educativo, las tasas de morbilidad y mortalidad, el bienestar físico de los individuos, el estado dietario y nutricional, la incidencia y prevalencia de enfermedades y vectores causantes de estas, entre otros.

Análogamente, en la perspectiva interpretativa de la investigación, la calidad de vida es vista desde la forma y las oportunidades de acceso a los servicios públicos domiciliarios, pero además en salud y educación, para lo cual el poder adquisitivo es una estrategia para el logro de estos.

Por otra parte, los indicadores de morbilidad y mortalidad han sido un problema social universal; en el caso de mostrar indicadores elevados, las expectativas de vida y salud son casi nulas y, en consecuencia, no hay condiciones mínimas de calidad de vida. Entonces, la calidad de vida es una consecuencia de los promedios de vida longeva, la salud tiene una incidencia directa en la tranquilidad de las personas y sus relaciones con la sociedad, las cua- les acompañadas de una dieta saludable y condición nutricional son necesarias para rendimientos laborales, académicos y deportivos.

Es significativo, entonces, que un estado dietario incide en la salud y el bienestar de las personas, al tiempo que determina las satisfacciones de necesidades de alimentación al proporcionar las energías indispensables para las actividades diarias del ser humano, pues esta se convierte en un bien fundamental relacionado con la salud y un medio para la satisfacción de muchas necesidades, en consecuencia, alcanzar una calidad de vida.

Vista la calidad de vida desde el texto de Salvador Rueda (1996), esta se caracteriza por una situación de existencia y oportunidades, expectativas, capacidades y necesidades del individuo, las afirmaciones de este autor hacen posible plantearse el siguiente interrogante: ¿las expectativas de las vivencias de los estudiantes aumentan su calidad de vida? En respuesta a este interrogante, se esbozan los resultados a partir de los comentarios que se exponen a continuación:

El crecimiento profesional, condición prometedora ${ }^{3}$, es una elección de transformación amplia del grado de satisfacción; en este caso, la evolución en la formación académica o capacitación, le proporcionan al graduado oportunidades laborales con beneficios para el mejoramiento de la calidad de vida. La idea es percibir la educación permanente en el individuo, continuar con niveles de posgrados y lograr transformar la condición profesional,

3 Entrevista con estudiantes de contaduría pública de los niveles VIII y X de la Universidad Cooperativa de Colombia, sede Santa Marta. 
factores que garantizan la consecución de satisfactores para la calidad de vida.

La satisfacción de necesidades para ser alegre y agradecido aumenta la calidad de vida, pero de manera efectiva, acerca a la felicidad. La satisfacción de necesidades facilita la tranquilidad y la armonía que aumentan la calidad de vida y se distingue entre los más acertados: el mejoramiento de los medios para alcanzar los satisfactores incrementa la satisfacción en su alcance, al tiempo que media la calidad de vida.

Todo lo anterior apunta a que con la formulación del proyecto de vida, se plantean las metas para alcanzar los satisfactores de necesidades como medio para merecer la calidad de vida. Por las consideraciones anteriores, es posible confirmar que la satisfacción de necesidades básicas dignas eleva la calidad de vida, que el logro de los satisfactores de necesidades tiene una relación de dependencia con las decisiones que se tomen para alcanzarlos y que sus resultados inciden en la calidad de vida.

La investigación apuntó a la construcción de indicadores sociales útiles a la contabilidad social que aporte a la toma de decisiones en programas para la calidad de vida bajo el enfoque del desarrollo a escala humana en los presupuestos planteados por Manfred Max-Neef, Antonio Elizalde y Martín Hopenhayn (2010). Para estos autores, la calidad de vida depende de cómo se satisfacen las necesidades fundamentales y se potencien los satisfactores y bienes económicos. En la presente propuesta ha de entenderse, como ya quedó dicho, que las necesidades no solo son carencias, sino también — simultáneamente- potencialidades humanas individuales y colectivas. Los satisfactores, por otra parte, son formas de ser, tener, hacer y estar, de carácter individual y colectivo, convenientes a la actualización de necesidades. Por último, los bienes económicos son objetos $\mathrm{y}$ artefactos que permiten afectar la eficiencia de un satisfactor, lo cual altera el umbral de actualización de una necesidad, ya sea en sentido positivo o negativo.

De acuerdo a la representación propuesta por Manfred Max-Neef, los resultados de la investigación abordaron las preferencias de los estudiantes, analizadas en la matriz de necesidades existenciales y axiológicas que ayudan al mejoramiento de la calidad de vida, formuladas en la tabla 1.

La matriz señala, en la columna del ser los atributos personales o colectivos que se expresaron como sustantivos; en la del tener, registra instituciones, normas, mecanismos y herramientas; en la del hacer, reconoce acciones personales o colectivas que pueden ser expresadas como verbos; y en la del estar, señala espacios y ambientes. Los resultados expresan las preferencias de los estudiantes, se agrupan de acuerdo a lo manifestado en términos de favoritismos por los satisfactores de las necesidades existenciales y axiológicas por parte del grupo focal en tres niveles de selección.

En este apartado se infiere el reconocimiento de los satisfactores de necesidades existenciales, que se potencian a partir de las necesidades axiológicas para la calidad de vida, coincidiendo con lo planteado por Manfred Max-Neef. Además se concluye que la calidad de vida como tema de investigación para políticas empresariales asociada a la contabilidad social, es un proceso que interviene para fortalecer líneas de investigación en el quehacer académico. 
INDICADORES DE CONTABILIDAD SOCIAL / F. GONZÁLEZ, D. LOBATÓN, G. POLO / 505

\begin{tabular}{|c|c|c|c|c|}
\hline $\begin{array}{l}\text { Necesidades } \\
\text { existenciales }\end{array}$ & Ser & Tener & Hacer & Estar \\
\hline Subsistencia & Salud física & Alimentación & Alimentar & Entorno vital \\
\hline & Salud mental & Trabajo & Trabajar & Entorno social \\
\hline Protección & $\begin{array}{l}\text { Cuidado } \\
\text { Autoestima }\end{array}$ & $\begin{array}{l}\text { Seguridad social } \\
\text { Sistema de salud } \\
\text { Familia }\end{array}$ & Cooperar & $\begin{array}{l}\text { Contorno vital } \\
\text { Contorno social } \\
\text { Morada }\end{array}$ \\
\hline Afecto & $\begin{array}{l}\text { Autoestima } \\
\text { Respeto } \\
\text { Tolerancia } \\
\text { Humor }\end{array}$ & $\begin{array}{l}\text { Amistad } \\
\text { Pareja } \\
\text { Familia }\end{array}$ & $\begin{array}{l}\text { Hacer el amor } \\
\text { Expresar emociones } \\
\text { Compartir }\end{array}$ & $\begin{array}{l}\text { Privacidad } \\
\text { Espacio de encuentro } \\
\text { Intimidad } \\
\text { Hogar }\end{array}$ \\
\hline Entendimiento & $\begin{array}{l}\text { Conciencia } \\
\text { crítica } \\
\text { Disciplina } \\
\text { Racionalidad }\end{array}$ & Políticas educacionales & $\begin{array}{l}\text { Investigar } \\
\text { Analizar }\end{array}$ & $\begin{array}{l}\text { Universidades } \\
\text { Familia }\end{array}$ \\
\hline Participación & $\begin{array}{l}\text { Adaptabilidad } \\
\text { Solidaridad } \\
\text { Disposición } \\
\text { Respeto }\end{array}$ & $\begin{array}{l}\text { Responsabilidades } \\
\text { Obligaciones }\end{array}$ & $\begin{array}{l}\text { Compartir } \\
\text { Dialogar }\end{array}$ & Familia \\
\hline Ocio & $\begin{array}{l}\text { Imaginación } \\
\text { Humor } \\
\text { Tranquilidad }\end{array}$ & $\begin{array}{l}\text { Juegos } \\
\text { Fiestas } \\
\text { Calma }\end{array}$ & $\begin{array}{l}\text { Soñar } \\
\text { Relajarse }\end{array}$ & $\begin{array}{l}\text { Privacidad } \\
\text { Tiempo libre } \\
\text { Paisajes }\end{array}$ \\
\hline Creación & Imaginación & $\begin{array}{l}\text { Habilidades } \\
\text { Destrezas }\end{array}$ & Trabajar & $\begin{array}{l}\text { Talleres } \\
\text { Espacios de expresión }\end{array}$ \\
\hline Identidad & $\begin{array}{l}\text { Pertenencia } \\
\text { Autoestima }\end{array}$ & $\begin{array}{l}\text { Costumbres } \\
\text { Valores }\end{array}$ & $\begin{array}{l}\text { Comportarse } \\
\text { Integrarse } \\
\text { Conocerse }\end{array}$ & $\begin{array}{l}\text { Entorno de la } \\
\text { cotidianidad } \\
\text { Ámbitos de } \\
\text { pertenencia } \\
\text { Etapas madurativas }\end{array}$ \\
\hline Libertad & $\begin{array}{l}\text { Autoestima } \\
\text { Tolerancia }\end{array}$ & Tranquilidad & Conocerse & $\begin{array}{l}\text { Espacios de la } \\
\text { cotidianidad }\end{array}$ \\
\hline
\end{tabular}

Tabla 1

Matriz de alta preferencia de necesidades existenciales y axiológicas

Fuente: elaboración propia

\section{Aproximación a la construcción de indicadores sociales de calidad de vida útiles a la contabilidad social}

A partir de la conceptualización de indicadores por varios autores entre ellos, Juan Cristóbal Bonnefoy (2006), quien lo define como la unidad de medida que permite calcular el alcance de una meta; por su parte, Ernesto Cohen y Ro- lando Franco (1992) admiten el concepto como las unidades de análisis en una evaluación, con base en los cuales se puede llegar a establecer un juicio fundado (Ventosa-Pérez, 1992) como la medida específica (explícita) y objetivamente verificable de los cambios o resultados de una actividad y (Ander-Egg, 1990), para demarcar ciertas condiciones o requisitos que deben 
cumplir los indicadores; entre los más significativos, independencia, objetividad, accesibilidad, sensibilidad y validez.

La población participativa en la investigación asumió una postura con los referentes teóricos señalados en el párrafo anterior y formuló indicadores que atienden a que deben establecerse unas metas con unos insumos, unos procedimientos previamente determinados y unos plazos para alcanzar los logros esperados.

Sin embargo, no debe perderse de vista que un aspecto determinante en la investigación se asumió haciendo énfasis en la construcción de indicadores cualitativos de calidad de vida que sirvan de complemento a los tradicionales (los cuantitativos); coincidiendo en lo referido por Pedro Delgado y Tulia Salcedo (2008), en este sentido, los procesos de construcción deben incluir aspectos importantes formulados por la misma sociedad.

\section{Formulación de indicadores de calidad de vida}

Los resultados de la investigación muestran en los anexos siguientes la base de datos de indica- dores sociales de calidad de vida útiles a la contabilidad social. De ahí se desglosó la interpretación conceptual y la construcción de indicadores de calidad de vida, que son aplicables para la medición e interpretación de la calidad de vida en una población estimada.

Los resultados orientan a la institución a definir políticas para crear los mecanismos que promuevan en la comunidad académica las estrategias que la motiven a incrementar o mejorar la calidad de vida de su población; así, la Universidad se convierte en promotora del desarrollo de su grupo de interés al pretender en ellos no solo los beneficios económicos, sino los medios para los satisfactores de necesidades existenciales y axiológicas.

Es preciso revelar que los indicadores agrupados en los satisfactores del estar, insignes como los de salud para la calidad de vida; del ser con los indicadores de educación para aumentar la calidad de vida; y del tener especificado en niveles de ingresos para definir la capacidad adquisitiva de agentes inciden en el mejoramiento de la calidad de vida. Para mayor ilustración, ver las tablas 2, 3 y 4. 
INDICADORES DE CONTABILIDAD SOCIAL / F. GONZÁLEZ, D. LOBATÓN, G. POLO / 507

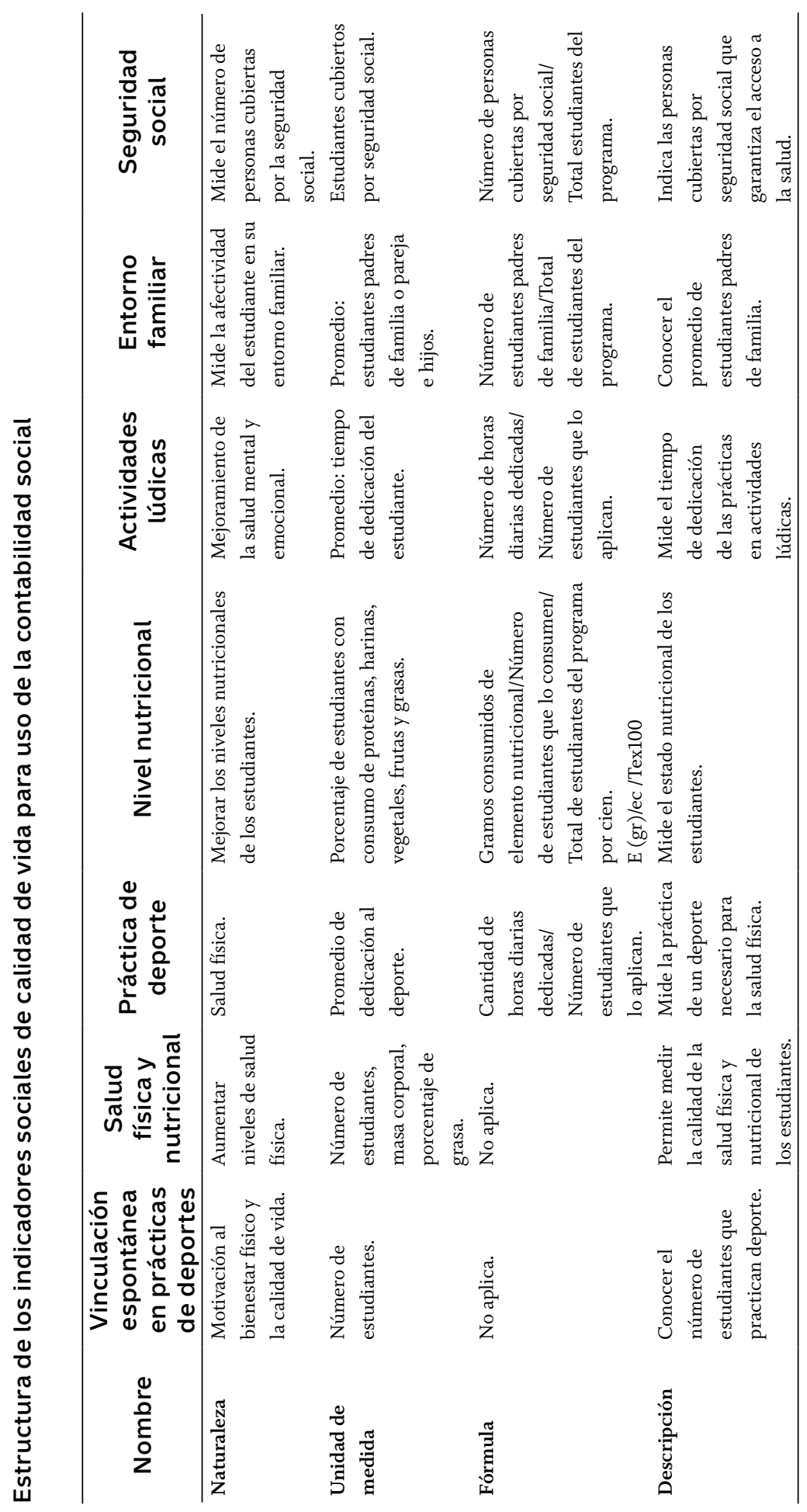


508 / VOL. 17 / NO. 44 / JULIO-DICIEMBRE 2016

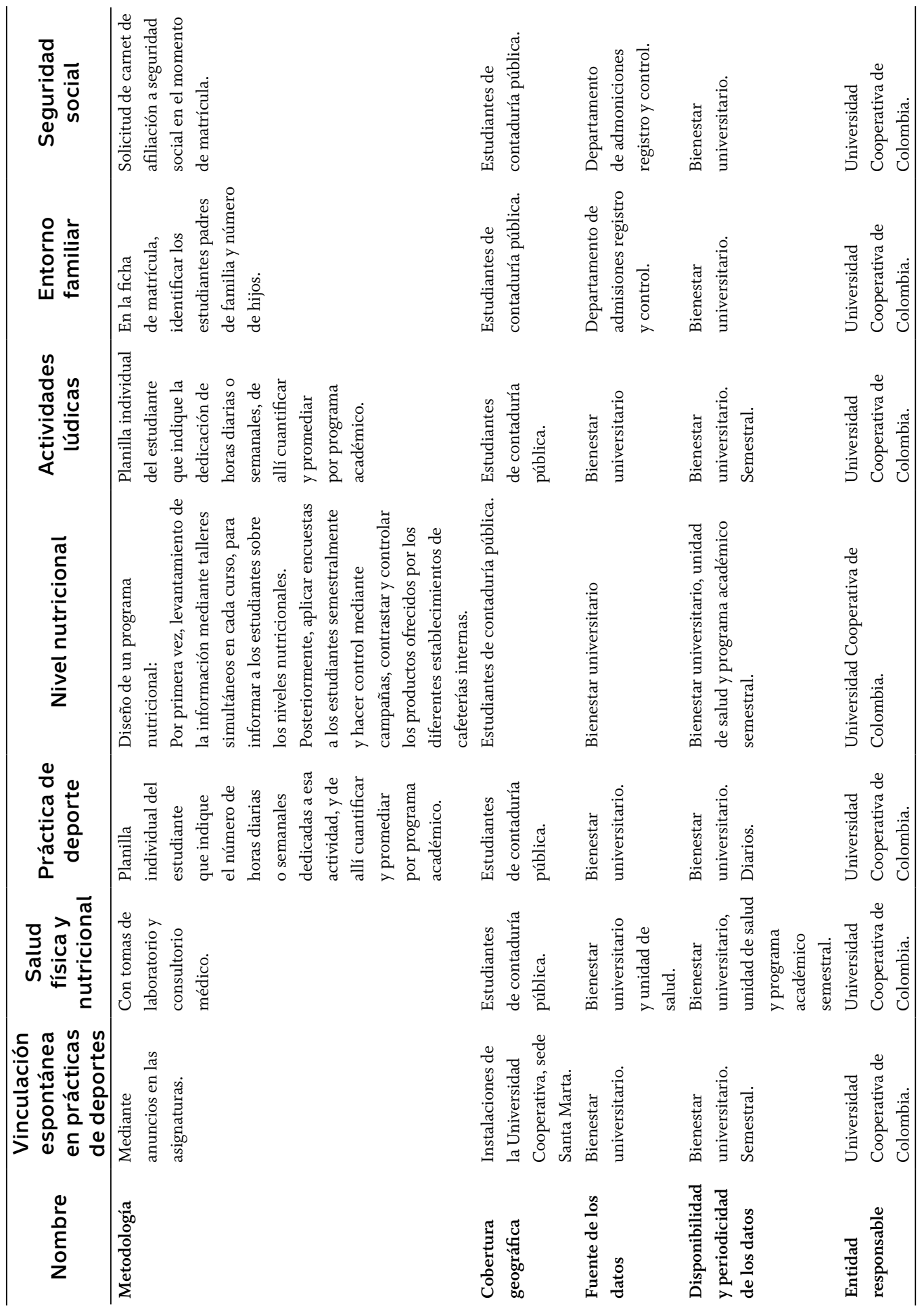




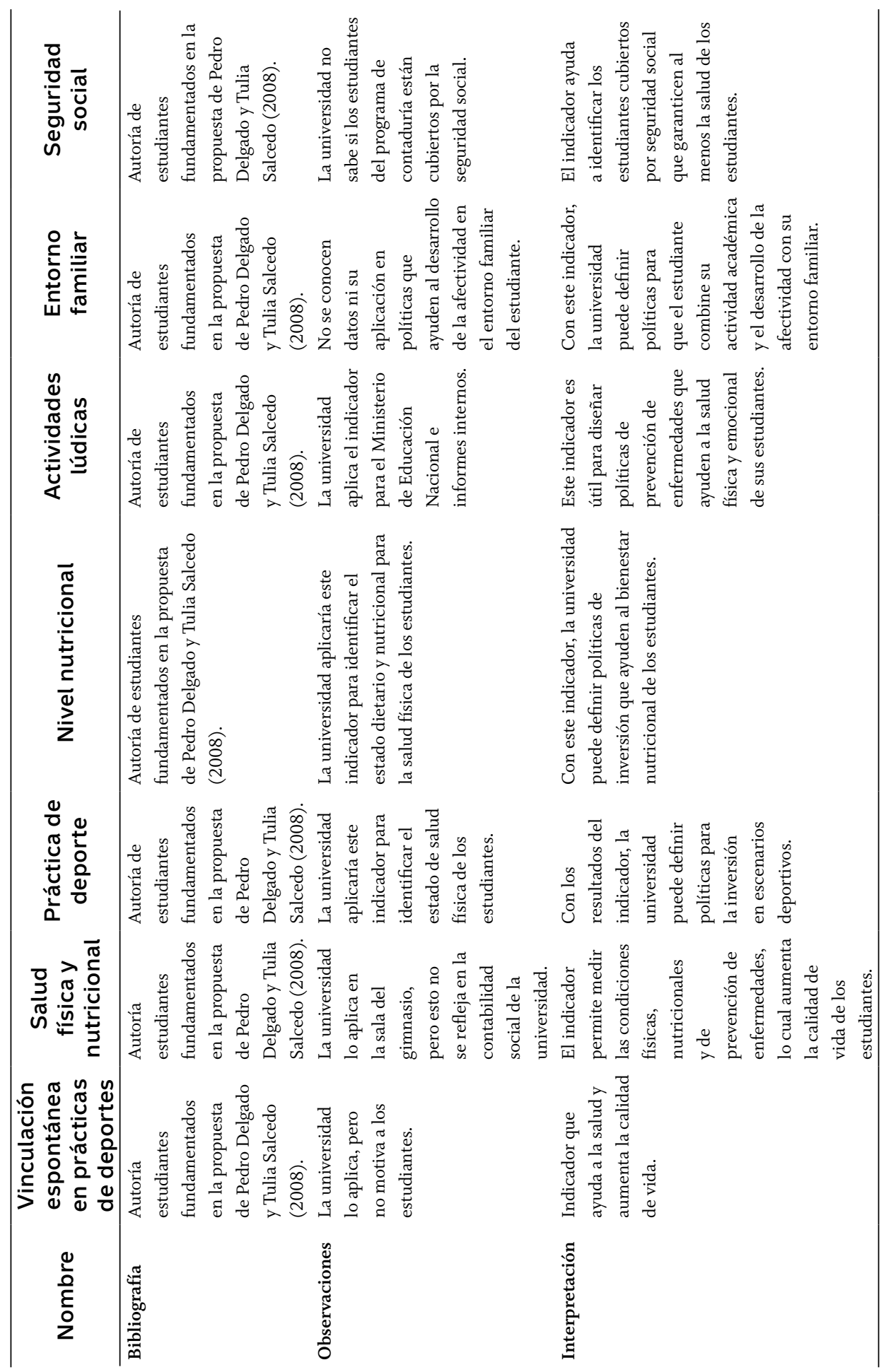


510 / VOL. 17 / NO. 44 / JULIO-DICIEMBRE 2016
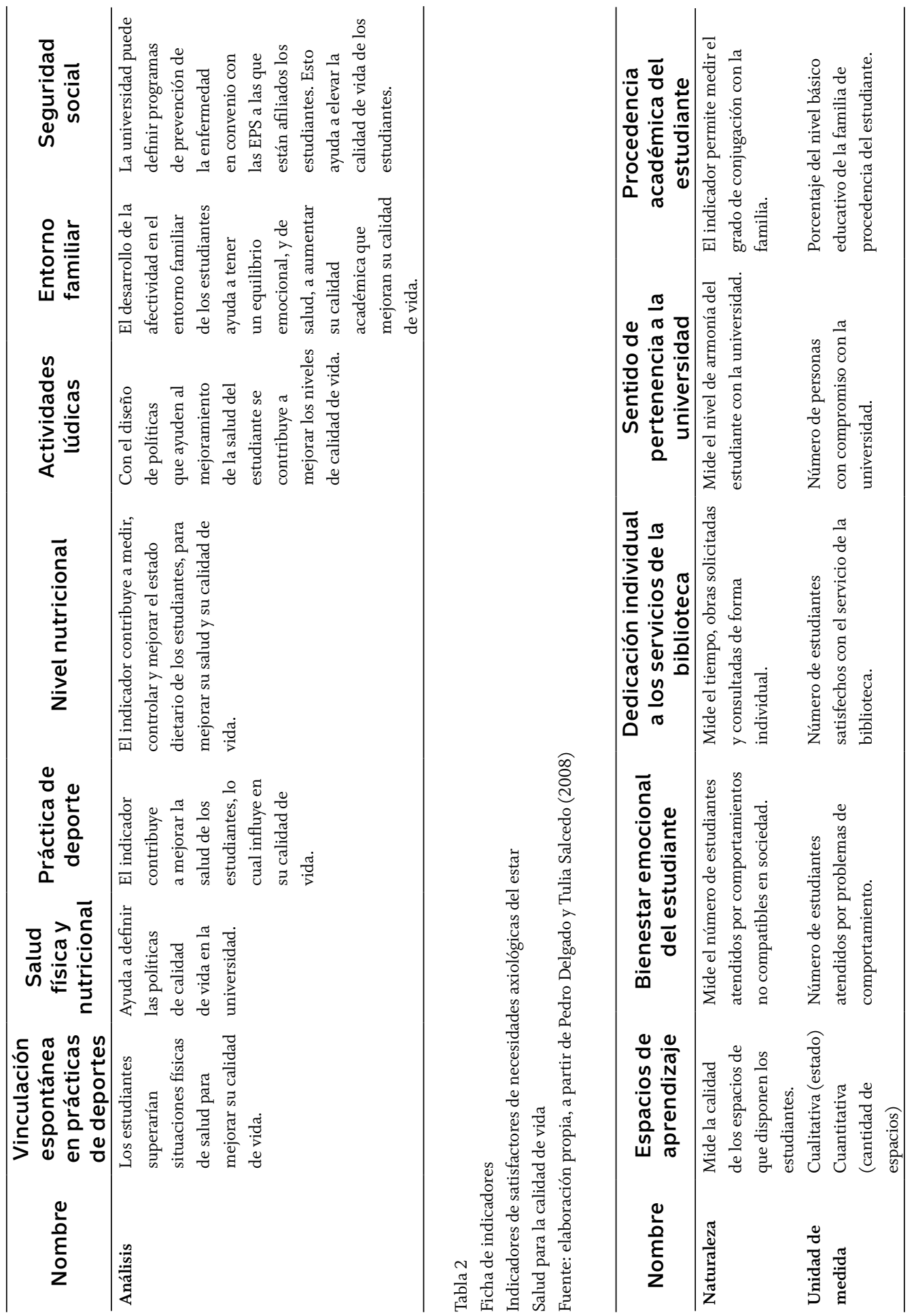


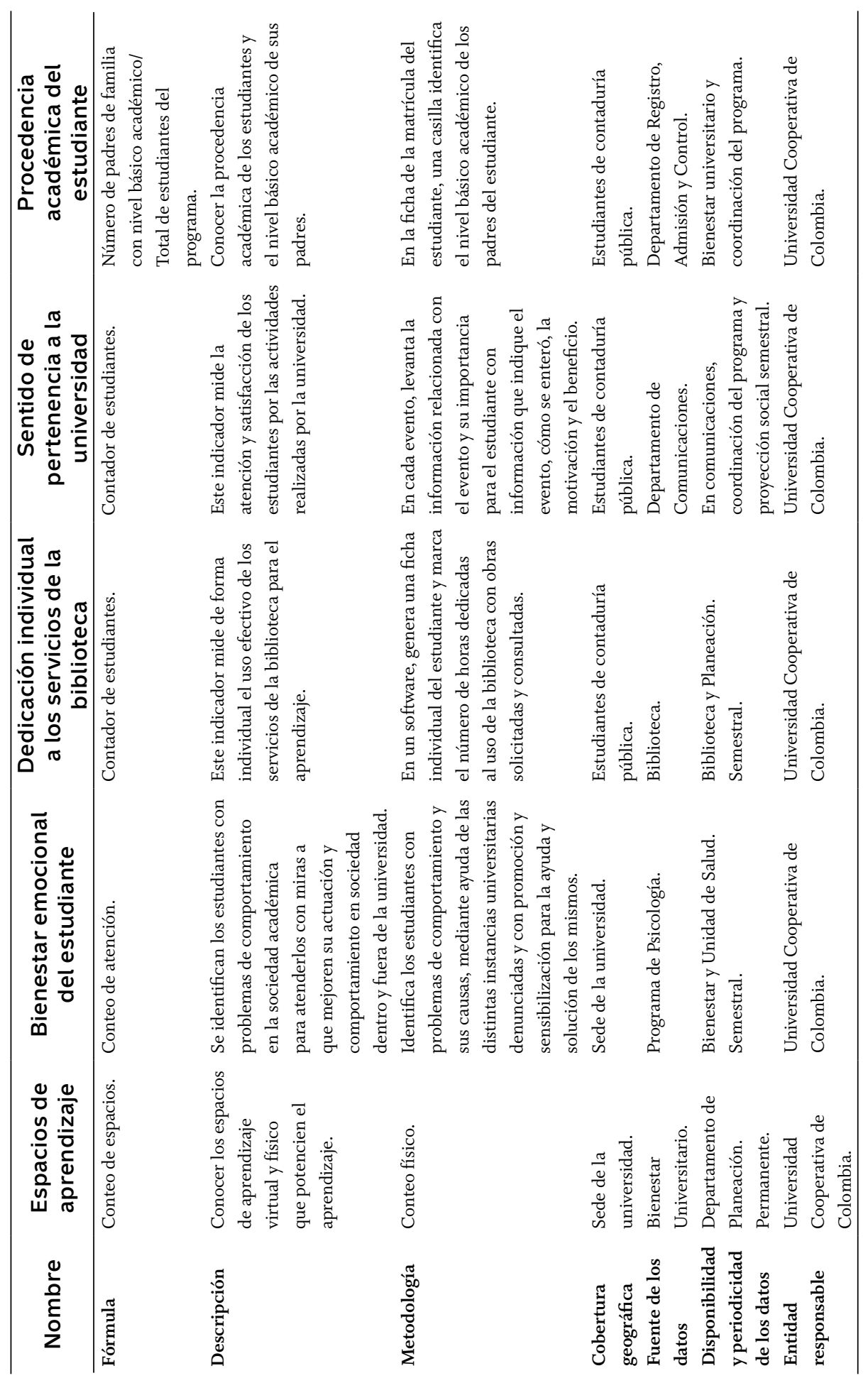


512 / VOL. 17 / NO. 44 / JULIO-DICIEMBRE 2016

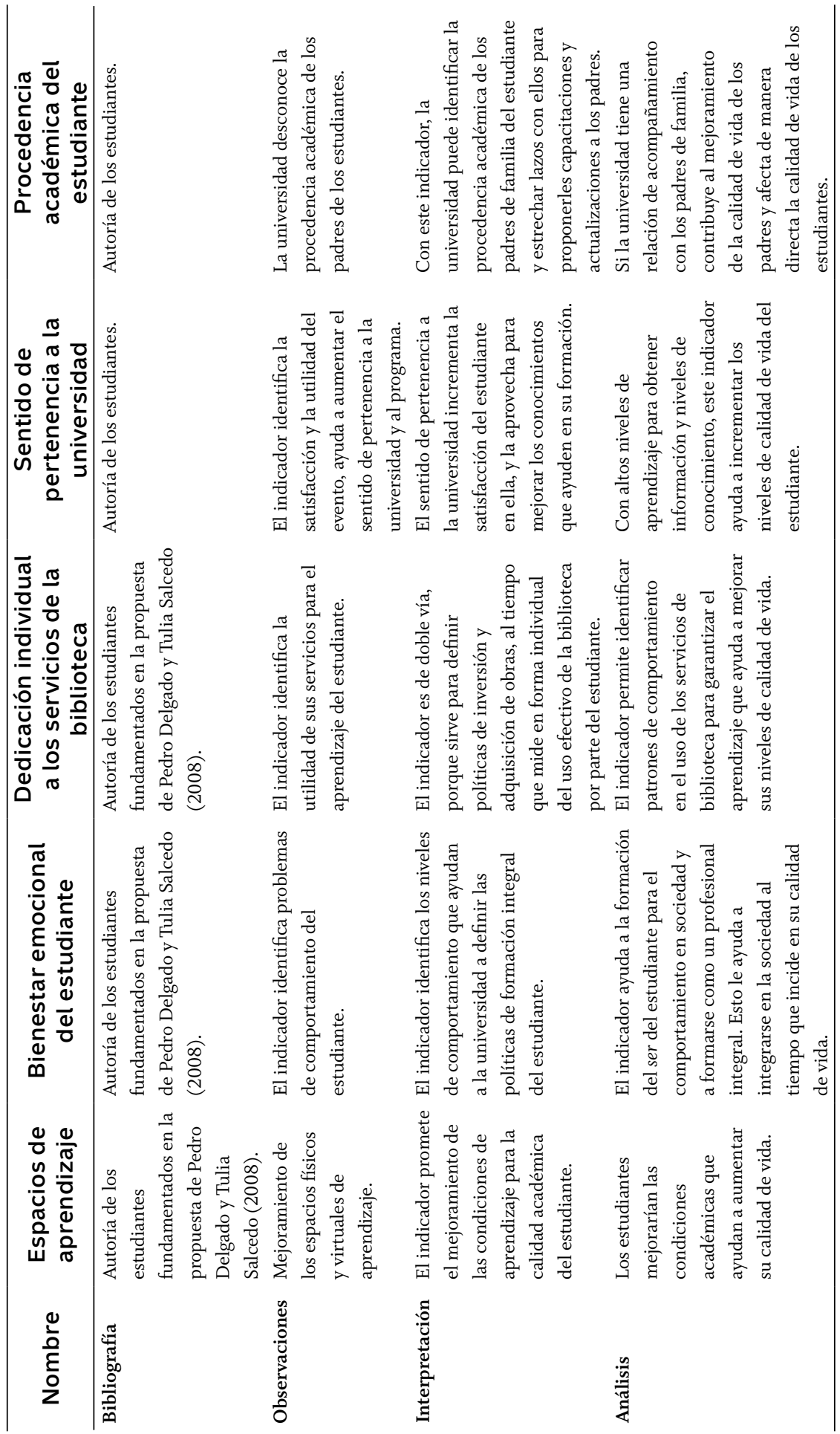

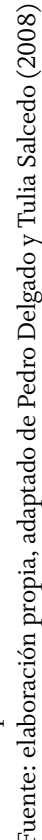




\section{INDICADORES DE CONTABILIDAD SOCIAL / F. GONZÁLEZ, D. LOBATÓN, G. POLO / 513}

\begin{tabular}{|c|c|}
\hline Nombre & Estabilidad económica. \\
\hline Naturaleza & Mide el poder adquisitivo del estudiante. \\
\hline Unidad de medida & Ingreso promedio de los estudiantes. \\
\hline Fórmula & Total ingresos estudiantes/Total de estudiantes. \\
\hline Descripción & $\begin{array}{l}\text { Indicador cuantitativo que mide los ingresos de los estudiantes para } \\
\text { definir su capacidad adquisitiva. }\end{array}$ \\
\hline Metodología & $\begin{array}{l}\text { Por medio de encuestas semestrales que pueden ser incluidas en los } \\
\text { formatos de matrícula para alimentar las bases de datos de Bienestar } \\
\text { universitario. }\end{array}$ \\
\hline Cobertura geográfica & Todos los estudiantes del programa de contaduría pública. \\
\hline Fuente de los datos & Departamento de admisiones, registro y control. \\
\hline Disponibilidad y periodicidad de los datos & Bienestar universitario, semestral. \\
\hline Entidad responsable & Universidad Cooperativa de Colombia \\
\hline Bibliografía & $\begin{array}{l}\text { Construcción por los estudiantes fundamentados en la propuesta de } \\
\text { Pedro Delgado y Tulia Salcedo (2008). }\end{array}$ \\
\hline Observaciones & Permite medir el nivel de estabilidad económica del estudiante. \\
\hline Interpretación & $\begin{array}{l}\text { Permite identificar los niveles de ingresos para estudios de calidad de } \\
\text { vida. }\end{array}$ \\
\hline Análisis & $\begin{array}{l}\text { El indicador de estabilidad económica es útil en la medición del poder } \\
\text { adquisitivo del estudiante para dar rasgos de calidad de vida de los } \\
\text { estudiantes. }\end{array}$ \\
\hline
\end{tabular}

Tabla 4

Ficha de indicadores

Indicadores de satisfactores de necesidades existenciales y axiológicas del tener

Nivel de ingresos para definir capacidad adquisitiva

Fuente: elaboración propia

\section{Relación entre los indicadores sociales,} la contabilidad social y la calidadde vida

Para explicar la relación entre indicadores sociales, contabilidad social y calidad de vida, es necesario entender inicialmente, el concepto de la respondabilidad: traduce la rendición de cuentas tanto del dinero como del compromiso moral y legal ante otros. El término rendición de cuentas proviene del latín accomptare, que significa que cuenta y de computare que es calcular, y a su vez deriva de putare que quiere decir contar. El concepto aparece en los años 60 en Estados Unidos y en los 70 llega a Europa, pero ha sido más desarrollado por la cultura inglesa durante los últimos años.
Hay diversas conceptualizaciones de respondabilidad. Según Joseph G. Jabbra y O. P. Dwivedi (1989), hay ocho (8) tipos de rendición de cuentas:

Para Andreas Schedler (1999), hay matices que separan los dos conceptos: accountability y rendición de cuentas. El accountability conlleva un sentido claro de obligación, la noción de rendición de cuentas parece sugerir que se trata de un acto voluntario, de una concesión generosa del soberano que rinde cuentas por virtud y voluntad propia, no por necesidad. Podemos precisar entonces que accountability es la rendición obligatoria de cuentas. 

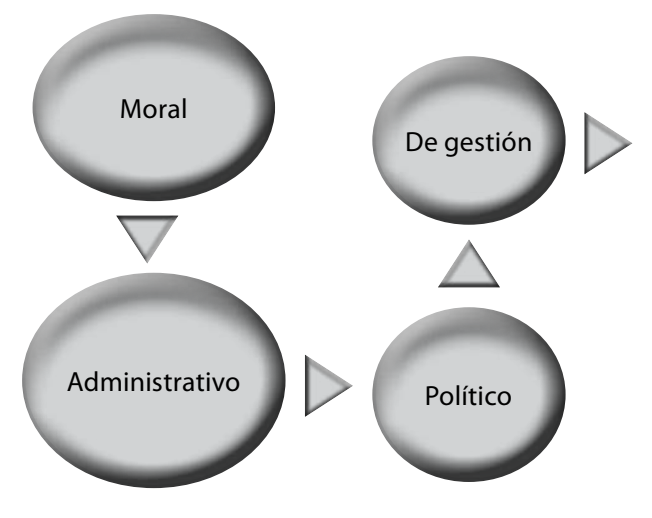

Gráfico 2

Tipos de rendición de cuentas

Fuente: Daulis Lobatón (2014)

Inicialmente, rendir cuentas en el ámbito administrativo y gerencial era concebido netamente como una acción fiscalizadora; aludía al informe "contable" que debían presentar los administradores a los dueños de la empresa o los funcionarios públicos al Estado. Esto se enuncia para justificar el modo de presentar la información al público de interés a estos indicadores que pretenden la mejora de la calidad de vida de los estudiantes. En esta rendición de cuentas priman la transparencia en la información y su adecuada comunicación.

Tal como se comentó en los resultados de la investigación, las nociones de contabilidad social en la población objetivo de investigación, desde las perspectivas teóricas de Marco Antonio Machado (2004), M. Reg Mathews (1993) y Mónica María Valencia (2004), orientaron la identificación de la categoría conceptual contabilidad social, en la percepción del objeto de estudio y los argumentos para las dimensiones en la identificación de los indicadores de contabilidad social.

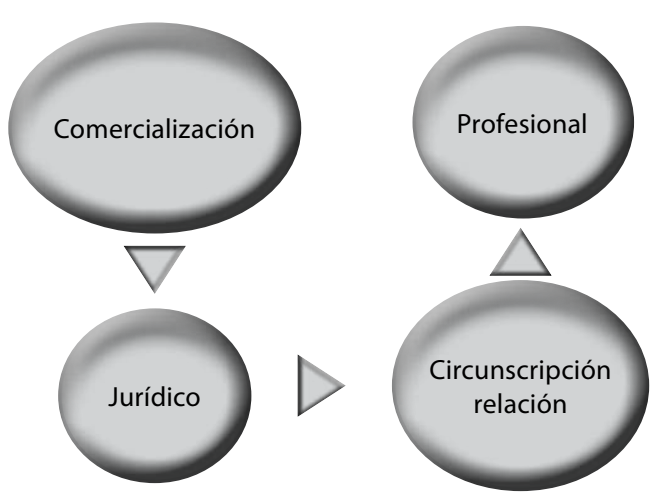

Los indicadores de calidad de vida se fundan en el insumo de la contabilidad social y tienen una relación directa con la información financiera presentada en la contabilidad financiera, sustrato para inversión en programas de desarrollo adecuados al mejoramiento de la calidad de vida en los grupos de interés de la Universidad representados en la comunidad académica; para este caso particular, los estudiantes del programa de contaduría de la Universidad Cooperativa de Colombia, los que al tiempo sirvan de instrumento de análisis e interpretación de los estados financieros, por medio de ellos y simultáneamente con el balance social, útiles para la toma de decisiones en materia de políticas, planes y programas de mejoramiento de la calidad de vida para sus grupos de interés, como se muestra en el gráfico 3. Sistema de información de la contabilidad social.

Luego, los indicadores sociales de calidad de vida útiles a la contabilidad social de la Universidad contexto de estudio constituyen un elemento fundamental para definir y construir 
el desarrollo de su comunidad, entendiendo la materialización de su responsabilidad social universitaria y la forma de respondabilidad de la información financiera, un camino hacia la contribución del desarrollo regional, ver y reflexionar en el gráfico 4.

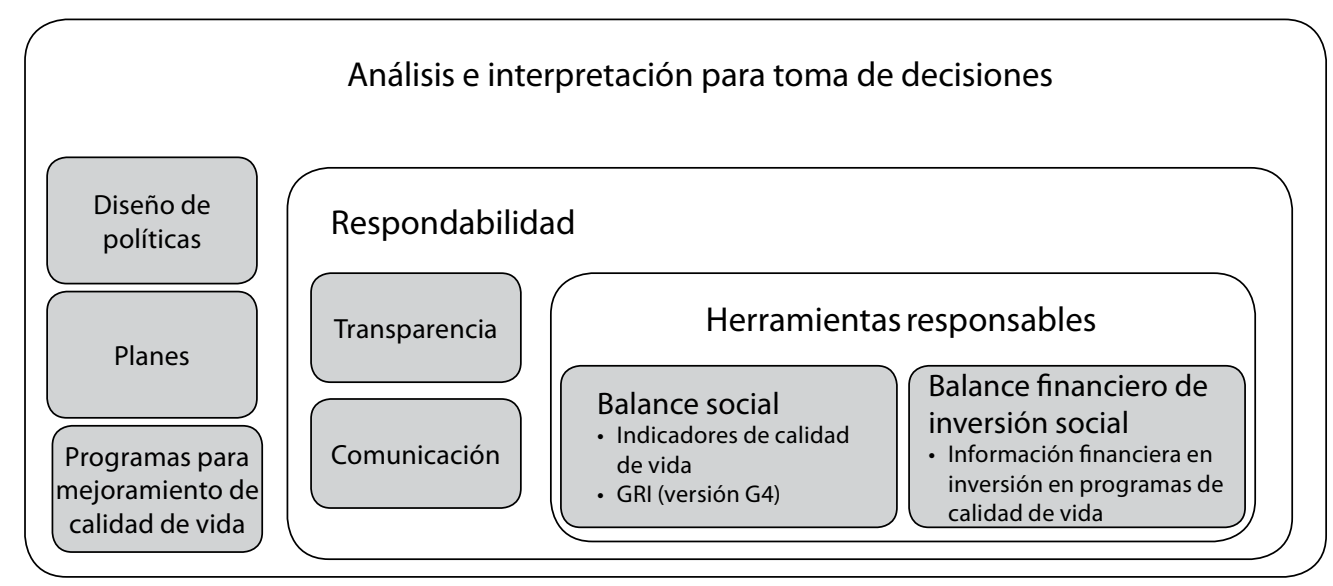

Gráfico 3

Sistema de información de la contabilidad social

Fuente: elaboración propia, a partir de Daulis Lobatón (2014)

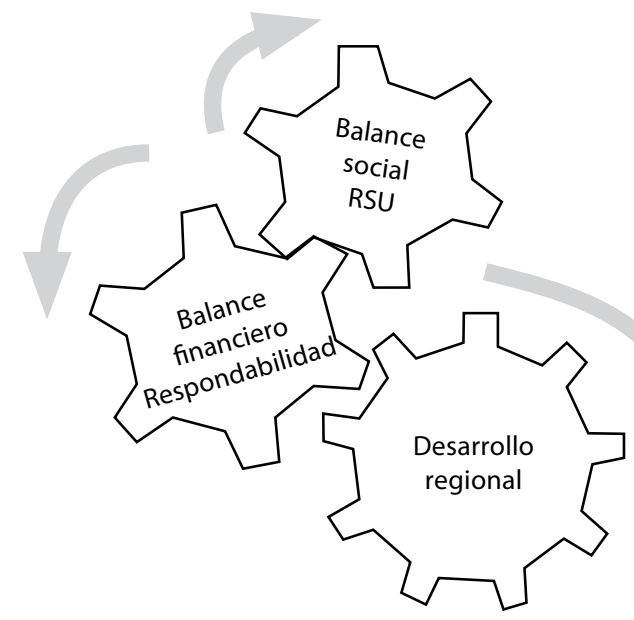

Gráfico 4

Utilidad de los indicadores de calidad de vida

Fuente: elaboración propia 


\section{Conclusiones}

Por los resultados de la investigación y a partir de los datos recabados con los participantes puede concluirse que:

- En la contabilidad social, se puede observar una aproximación hacia una visión de la contabilidad con rasgos de información social y cualitativa diferente a la convencional mostrada en los estados financieros, con aspectos no económicos de la organización, al tiempo que permite responder por sus actuaciones frente a la comunidad o entorno en donde actúa, y en lo relacionado con la gestión empresarial como su interacción con la sociedad.

- Coincidiendo con los enfoques de tres autores guías en el desarrollo de la investigación (Machado, 2000, 2004; Mathews, 1993; Valencia, 2004), la contabilidad social se interpreta como un instrumento útil para la toma de decisiones en el diseño de políticas empresariales privadas y públicas desde el mismo Estado, para el diseño y desarrollo de planes y programas concretos desde la realidad misma, que surge de los resultados, por la aplicación de indicadores de calidad de vida para la evaluación de las actuaciones empresariales lo que permite que la información relacionada se convierta en un elemento generador de desarrollo, infiriendo:

- Que el concepto de contabilidad social es una forma de expresión de responsabilidad social empresarial (RSE).

- La contabilidad social ayuda a cumplir el principio de la completitud, al reflejar as- pectos de medio ambiente necesario para minimizar la contaminación ambiental y otras que tienen qué ver con los actos empresariales.

- La contabilidad social se constituye en práctica de responsabilidad social en la medida en que la empresa adquiere un mínimo de compromiso por hacer prácticas que impliquen actividades dirigidas o relacionadas con su entorno social y, estas beneficien o ayuden a la sociedad y se reflejan en la contabilidad.

- Que la contabilidad como sistema de información que fundamenta la responsabilidad social en las empresas, en el sustrato de rendición de cuentas en el ámbito administrativo y gerencial, se enuncia para justificar el modo de presentar la información al público de interés, y que sobre la base de indicadores con miras al mejoramiento de la calidad de vida, prima la transparencia en la información y la comunicación.

- La práctica de la contabilidad social exige una nueva visión en el ejercicio de la contaduría pública. Por eso, de igual forma ayuda a la formación de un contador integral, que le lleve a tener un concepto más amplio de la contabilidad, lo induce a manifestaciones conscientes con el medio ambiente, lo social y lo financiero.

- Los aspectos sociales, entendidos entre ellos capital humano e intelectual, le dan rasgos y características cualitativas a la contabilidad social y permiten ampliar su horizonte, le dan esencia como sistema de información, al tiempo que amplían el campo de actuación de los contadores. 
- Lo cualitativo entrelazado con lo cuantitativo mejora la información para una acertada toma de decisiones.

- El contador público que, actuando en el sistema de información contable integral es decir, que tenga en cuenta además de los aspectos financieros los sociales y ambientales, interviene en procesos que apuntan hacia el desarrollo sostenible, genera en las empresas y en su entorno respeto por la sociedad y el medio ambiente, con la capacidad transformadora de una información en términos de interés para la sociedad.

- Los indicadores de calidad de vida constituyen el insumo de la contabilidad social, por medio de ellos y simultáneamente con el balance social, son útiles en la toma de decisiones en materia de políticas, planes y programas de mejoramiento de la calidad de vida de sus grupos de interés, incluidos como grupo principal los estudiantes.

- Los indicadores de calidad de vida formarían parte del balance social, entendido este como instrumento que informa sobre la contribución de las organizaciones al objetivo del desarrollo sostenible.

\section{Referencias}

Ander-Egg, Ezequiel (1990). Evaluación de programas de trabajo social. Buenos Aires: Humanitas.

Araujo-Ensuncho, Jack Alberto (1995-2002). La contabilidad social. Medellín: Tiempo Gráfico.

Bonnefoy, Juan Cristóbal (2006). Indicadores de desempeño en el sector público. CEPAL.
Disponible en: http://www.cepal.org/ilpes/ noticias/paginas/2/23992/Indicadores\%20 de\%20Desempe\%C3\%B1o.pdf

Campos-Menéndez, Hernando (1978). El balance social. Cuadernos de Empresa, Asociación Cristiana de Dirigentes de Empresa (ACDE), 2, Separata Revista de Empresa, 44, 35.

Cohen, Ernesto \& Franco, Rolando (1992). Evaluación de proyectos sociales. 2 ed., Ciudad de México: Siglo XXI Editores. Disponible en: http://www.evalua.cdmx. gob.mx/docs/gral/taller2015/S0102EPS.pdf Delgado, Pedro \& Salcedo, Tulia (2008). Aspectos conceptuales sobre los indicadores de calidad de vida. La sociología en sus escenarios, 17, 1-33. Disponible en: https:// aprendeenlinea.udea.edu.co/revistas/index. php/ceo/article/view/6803/6233

Departamento Nacional de Estadística, DANE (2013). Elementos metodológicos básicos para la selección, construcción, interpretación y análisis de indicadores. Documento Guía para el diseño, la construcción de indicadores, herramientas estadísticas para una gestión territorial más efectiva. Bogotá: Departamento Nacional de Estadística, DANE. Disponible en: https://www.dane. gov.co/files/sen/planificacion/cuadernillos/ IntroduccionDisenoConstruccion InterpretacionIndicadoresWeb.pdf Desarrollo de la Responsabilidad Social, DERES (2004). Manual de autoevaluación. Montevideo: Desarrollo de la Responsabilidad Social, DERES. Disponible en: http://www.csr360gpn.org/uploads/ files/resources/Manual_Autoevaluacion.pdf 
Estes, Ralph W. (1972). Socio-Economic Accounting and External Diseconomies. The Accounting Review, 47 (2), 284-290.

Francke, Marfil \& Morgan, María de la Luz (1995). La sistematización: apuesta por la generación de conocimientos a partir de las experiencias de promoción. Lima: Escuela para el Desarrollo. Disponible en: http://centroderecursos.alboan.org/ sistematizacion/es/registros/5876-lasistematizacion-apuesta-por

Fundación Entorno, Empresa y Medio Ambiente (1998). Libro blanco de la gestión medioambiental en la industria española.

Madrid: Mundi-Prensa.

Global Reporting Initiative, GRI (2015). Guía para la elaboración de Memorias de Sostenibilidad, cuarta versión (G4). Disponible en: https://www. globalreporting.org/resourcelibrary/ Spanish-G4-Part-One.pdf

Gómez-Vela, María \& Sabeh, Eliana (2000). Calidad de vida. Evolución del concepto y su influencia en la investigación y en la práctica. Instituto de Integración en la Comunidad, INICO, Facultad de Psicología, Universidad de Salamanca, Integra, 9. Disponible en: http://inico.usal.es/integracontenidos-inico.aspx?num $=9$

Gray, Rob; Owen, Dave \& Adams, Carol (1996). Accounting and Accountability: Changes and Challenges in Corporate Social and Environmental Reporting. London: Prentice Hall.

Hernández-Sampieri, Roberto; FernándezCollado, Carlos \& Baptista-Lucio, Pilar (2010). Metodología de la investigación. $5^{\mathrm{a}}$ ed., México: McGraw-Hill. Disponible en: https://www.esup.edu.pe/descargas/ dep_investigacion/Metodologia\%20de $\% 20$ la\%20investigaci\%C3\%B3n\%205ta\%20 Edici\%C3\%B3n.pdf

Jabbra, Joseph G. \& Dwivedi, O. P. (eds.) (1989). Public Service Accountability: A Comparative Perspective. Hartford, Connecticut: Kumarian Press.

Lobatón, Daulis (2014). Responsabilidad social como acción tributaria en empresas del sector de la economía social y solidaria (tesis doctoral). Maracaibo, Venezuela: Universidad privada Dr. Rafael Belloso-Chacín.

Machado-Rivera, Marco Antonio (2000). Desarrollo científico de la contabilidad y calidad de vida. Revista Legis del Contador, 3, 127-165.

Machado-Rivera, Marco Antonio (2004). Dimensiones de la contabilidad social. Revista Internacional Legis de Contabilidad y Auditoría, 17, 173-218.

Mathews, Meg R. (1993). Socially Responsible Accounting. London: Chapman \& Hall. Max-Neef, Manfred; Elizalde, Antonio \& Hopenhayn, Martín (2010). Desarrollo a escala humana. Opciones para el futuro. Biblioteca CF+S. Disponible en: http:// habitat.aq.upm.es/deh/adeh.pdf

Pedreira-Pérez, Ricardo (1980). Nuevas ramas en la ciencia contable. Madrid: Biblioteca Ciencias Empresariales.

Perafán, Astrid Lorena \& Martínez-Dueñas, William Andrés (2004). Calidad de vida: una propuesta sistémica para su construcción. Argentina. Disponible en: http://www. equiponaya.com.ar/congreso2002/ 


\section{INDICADORES DE CONTABILIDAD SOCIAL / F. GONZÁLEZ, D. LOBATÓN, G. POLO / $\mathbf{5 1 9}$}

ponencias/astrid_lorena_perafan_ledezma. htm

Rey, Françoise (1978). Introduction à la comptabilité sociale. Paris: Imprimerie des Presses Universitaires de France à Vendôme.

Riahi-Belkaoui, Ahmed (1992). Accounting Theory. Sydney, Australia: Harcourt Brace, Australia.

Rueda, Salvador (1996). Habitabilidad y calidad de vida. Madrid. Disponible en: http:// habitat.aq.upm.es/select-sost/ac3.html Schedler, Andreas (1999). Conceptualizing Accountability. En Andreas Schedler, Larry Diamond \& Marc F. Plattner (eds.). The SelfRestraining State: Power and Accountability in New Democracies, 13-28. Boulder, London: Lynne Rienner Publishers.

United States, General Accounting Office, GAO (1986). CPA Audit Quality: Many Governmental Audits Do Not Comply with Professional Standards. Washington: General Accounting Office, GAO. Disponible en: http://www.gao.gov/products/AFMD-86-33 Valencia, Mónica María (2004). Teoría de la contabilidad social. Disponible en: http:// www.gestiopolis.com/canales2/finanzas/1/ consoimpli.htm\#mas-autor

Ventosa-Pérez, Víctor Juan (1992). Educación social: animación e instituciones. Madrid: CCS.

Verger i Planells, Antoni (2002). Sistematización de experiencias en América Latina: una propuesta para el análisis y la recreación de la acción colectiva desde los movimientos sociales. Revista de Educación, 343, 623-645. Disponible en: http://www.revistaeducacion. mec.es/re343/re343_26.pdf

- Fecha de recepción: 24 de agosto de 2015

- Fecha de aceptación: 23 de enero de 2016

- Disponible en línea: 14 de diciembre de 2016

\section{Para citar este artículo}

González-Castillo, Fredy; Lobatón-Polo, Daulis \& Polo de Lobatón, Gregoria (2016). Indicadores de contabilidad social con miras a diseñar políticas de mejoramiento de calidad de vida. Cuadernos de Contabilidad, 17 (44), 493-519. https://doi. org/10.11144/Javeriana.cc17-44.icsm 
